\title{
Brachyury-expressing Modified Vaccinia Ankara-TRICOM Vaccine
}

\author{
National Cancer Institute
}

\section{Source}

National Cancer Institute. Brachyury-expressing Modified Vaccinia Ankara-TRICOM

Vaccine. NCl Thesaurus. Code C116777.

A cancer vaccine composed of a replication-deficient, attenuated derivative of the vaccinia virus strain Ankara expressing both a CD8+ T-cell epitope from the brachyury protein and a triad of T-cell co-stimulatory molecules (MVA Brachyury-TRICOM), with potential immunomodulating and antineoplastic activities. Upon subcutaneous administration of the brachyury-expressing modified vaccinia Ankara (MVA)-TRICOM vaccine, the expressed brachyury protein induces specific CD8+ and CD4+ T-cell responses against brachyury-expressing tumor cells. This causes both tumor cell lysis and a decrease in the growth of brachyury-expressing tumor cells. Brachyury, a member of the T-box family of transcription factors that is overexpressed in numerous cancer cell types, is correlated with increased epithelial-mesenchymal transition (EMT), cancer resistance and cancer progression. TRICOM, a triad of three human T-cell co-stimulatory molecules, B7.1, ICAM-1 and LFA-3, enhances antigen-specific T-cell activation. 